such as lung trouble, particularly bronchial, liver derangement, or last, but not least, renal trouble; you had better leave the case to nature, and relieve symptoms by the many ways your art suggests, than by any act of yours endanger life. If you are not sure, as I said at an early part of this lecture, of doing good, be sure that you do no barm. The patient may die, but take care that he does not do so at the surgeon's hands.

By the same argument you will hesitate about performing any operation, that is not an urgent necessity to save life, upon any subject who has exhausted his powers by drink, or who is either a drunkard or an habitual spirit-drinker. Hesitate also about interfering with any great eater. But above all things hesitate about performing any operation that is not a necessity upon the subject of Bright's disease.

Remember, also, that operative surgery, although an important part, is only a part of surgery ; and recognise the fact that the higher duties of the surgeon are to be found outside the operative department and away from the operating table. But, at the same time, bear in mind, when the surgeon, through his higher faculties, comes to the conclusion that an operation is a necessity to save life, or is justifiable to prolong it or to render life more valuable, it is his bounden duty so to have educated his manual powers, so to have studied the mechanical part of his art and the necessities of the case he has to deal with, as to be able to carry out with all the skill of which the living matter he is dealing with is worthy the dictates of his own judgment; and let him be sure, if success does not crown his efforts, that failure can in no way be attributed to any want of ordinary skill, any want of care, or any want of preparation. For the ultimate result of an operation rests, without a shadow of doubt, upon the right execution of each step in it; and when each step has been efficiently performed the surgeon's duty has been fulfilled. But remember that a failure in any one of the steps of an operation, from the very beginning of the case up to the final dressing of the wound, as a rule, means failure in the whole, and that a want of atten. tion to what might appear to be a trivial matter may spoil what would otherwise have been a brilliant success; for success in operative surgery rests as much upon the right execution of so-called small points as of the large, and that surgeon is the most successful who, with the main object of his operation in view, looks most into details. By the operating surgeon, nothing that tends towards success should be looked upon as trivial-nothing so small as to be beneath his notice.

Gentlemen, I must now close my lecture, and I will do so by asking you to carry away the principles $I$ have attempted to enunciate, and to accept them as guides in your professional career. Ponder over them at your leisure, and so make them your own; take them into your minds and mentally digest them, so that they may become part and parcel of your nature, and find expression in the daily acts of your professional life. Bear in mind that all woundsaccidentally received or surgically produced-are healed by natural processes, and that all the surgeon can do in their treatment is to remove obstacles to natural repair, place wounded parts in the position in which natural repair is the best effected, and stimulate the process. Have unbounded faith in the restorative power of natural processes. Before you interfere in any case with things as you find them, always feel that the onus of interference rests with you, and that unless you can show good cause to your own mind why you should do so, you had better leave matters alone. Have a horror of meddlesome surgery, and a great respect for a do-nothing practice when no indications for doing, or for doing good, present themselves; but remember that by doing nothing judiciously you often do more good than by action, and that to know how to wait is a great power. When action is called for, act boldly and with decision, and let no vacillation spoil the practice your own honest judgment has pronounced to be right. Act in all things under a deep sense of the responsibility of your actions, and remember at all times that it is with a human life you are dealing.

In operative surgery let these feelings have their fullest influence, and in no case nor under any circumstances perform the simplest or the largest operation unadvisedly. Bear in mind that in the simplest operation there is a risk to life, and that under all circumstances that risk is to be recognised. Remember likewise that that risk is not to be run without a definite reason. Always recognise it yourselves, and see that it is made known to your patient or to his friends. Treat no operation as being absolutely free from danger, and never presume to guarantee any result.

In deciding upon the propriety of an operation, always regard it from your patient's point of view and in his interests, and on no account allow yourself to be influenced by any professional or personal bias.

In selecting the operation to be performed, choose the one that fulfils the most closely the objects you have in view-viz., the removal of the disease that demands removal with the least danger to life and the least sacrifice of parts. On no account let any personal preference for an operation, or personal success in it, induce you to deviate from this rule.

In fact, gentlemen, do to your patients what you would have done to you were you in their place, with your own knowledge and appreciation of the risks with which the proposed surgical act is surrounded; for your profession is a noble one. Be careful that no selfish ends be allowed to spoil the beauty of its objects. Let no professional prejudice or narrowness creep in to mar the thorough goodness of its results. Let your practice of surgery be based upon principles, and let your principles of surgery be based upon a higher one, and let that higher principle be no less a one than that which binds us all together as men-as Christian men; for, if we be surgeons, let us not forget that we are Christian men as well, and let our professional conduct be governed by the same influences that govern our conduct in daily life.

If the objects of the surgeon are high-and who is there that can deny it? - surely the principles upon which bis acts are based should be high likewise. If the principles $I$ have inculcated are high-and I admit they are,-let me remind you they are so only in order that they may help you onwards to fulfil manfully the noble ohjects for which you bave entered at this hospital, and, as surgeons, to do something towards the relief of human suffering.

\section{ON A FATAL CASE OF BLOOD-POISONING OF UNCERTAIN NATURE, PRESENTING SEVERAL UNUSUAL CHARACTERS.}

Br DYCE DUCKWORTH, M.D., F.R.C.P.,

ASSISTANT-PEYSICIAN TO ST. BARTHOLOMEW'S HOSPITAL; BXAMINBR IN PRACTICE OF PHYSIC IN THE DNIVERSITX OF RDINBURGH.

THE case of which the following particulars are subjoined was one presenting several features of remarkable interest, and it therefore deserves publication. It seems, indeed, not an easy task, judging purely by its clinical characters, to place it in any clearly defined nosological category; but the nearest approach to such an attempt has been made in the title given above. Mr. Steele of Reigate, under whose immediate care the patient was, has kindly supplied to me the early history of the case.

X. Y., aged twenty-one, a slightly built, fair-haired gentleman, on the $26 \mathrm{th}$ September, 1875 , began to complain of a noisy barking cough, and of some occasional spasmodic difficulty of swallowing. The day following he sought $\mathrm{Mr}$. Steele's advice for these symptoms, and he further com. plained of some fulness about his neck. That gentleman at once detected an enlargement of the thyroid gland, and, finding no other physical signs, attributed the troubles described to that particular affection. Mr. Y. had never been robust, but had had no illness of any importance till four years previously, when he had a severe attack of typhoid fever. During the summer he had been somewhat overworked, and had not had sufficient holiday relaxation. The swelling was ordered to be painted with tincture of iodine, and a mixture was given containing three-grain doses of iodide of potassium in an ounce of infusion of gentian. Confinement indoors was also enjoined. It was noted that the action of the heart was somewhat feeble; pulse about 60 ; the akin was cool, and the appetite fairly good. The patient contrived to amuse himself in his room, and did not feel unwell. In the course of a few days the inspiration became gradually rather noisy, but was not 
diffcnlt; and there was slight "brassy" cough, with the expectoration of a little grey mucus. The voice was also hoarse.

On the 10 th of October I saw the case for the first time with Mr. Steele, and confirmed the above conditions. The thyroid body was then uniformly enlarged, symmetrical, hard, and firm. The finger could not be passed into the sternal notch. The lymphatic catena on the right side of the neck was enlarged, but not, or very slightly, upon the left side. There were no other enlarged lymphatic glands upon the body. The thyroid gland was only a little tender upon manipulation, and the integument over it was tense, cool, and non-adherent. The pulse was 60 per minute, regular, and the action of the heart was feeble. The tongue was a little furred, and a mawkish taste in the mornings was complained of. The bowels were comfortably relieved. The stomach was rather irritable, and there was a tendency to nausea. The chest was everywhere resonant on percussion, with the exception of some slight dulness under the manubrium of the sternum. The breath-sounds were modified generally by an apparently conducted tracheal note, but they were more shrill in the right suprascapular and infrascapular regions. The roice-sounds in these situations were also louder and more bronchial than on the left side.

Two small flattened tumours were found on the abdomen on the left anterior lumbar region, dusky-grey in hue, rounded and well-defined. They were tender when pinched up, and were distinctly in the integument. These had been observed for about ten days. The legs were natural in all respects. The spleen was not at all enlarged, and the liver was of normal dimensions. There had been a little soreness of throat and oedema of the uvula, and painting with equal parts of tincture of perchloride of iron and glycerine had been practised for relief of this. The urine was natural in quantity and appearance. The patient got up each day, and changed his room. No dysphagia, or very little, was complained of, but there was some irritability of stomach, and also occasional tendency to faintness and retching.

It was decided to increase the iodide of potassium to five grains for a dose, and to give as much of the carbonate of ammonia with it in infusion of gentian. The thyroid swelling was still painted with tincture of iodine.

On the 13 th October there was no marked change, but some coryza had occurred, and the iodide was evidently illborne. About this time paroxysms of pain were complained of, issuing from the right side of the seventh cervical vertebra and shooting into the front of the right shoulder. At times these attacks were very severe. Opiates were given every four hours for the relief of this pain, and with some benefit. The nights were bad and the attacks of pain and retehing were more frequent at night. The ointment of biniodide of mercury was now rubbed into the thyroid swelling. One application of this, however, caused vesication, and no more was employed. The breathing continued noisy, and at times there were short paroxysms of dyspncea together with the attacks of pain and retching, requiring semi-erect posture in bed. The cervical glands continued to enlarge a little. During the two following days no decided change occurred. The pain still proved very annoying, and persisted in the same situation, and the faintness and retching continued. Usually a little bilious mucus was brought up. About the 15 th October it was distinctly to be observed that the swelling of the thyroid gland was diminished and the whole organ was softer and less tense than before, perhaps even softer than a bealthy sland, but the enlargement remained of symmetrical character, and there were still signs of tracheal and bronchial yressure as before. Some grey pearly masses of mucus wer brought up after coughing, but the cough was not at all urgent. On the 17th October the pulse was 60 , feeble temperature normal; urine natural in appearance and void of albumen. The blood was examined microscopically, and the proportion of white cells was found to be normal, the sed globules forming healthy rouleaux. The same dulness, and no more, was found at the manubrium on percussion, the resonance being good elsewhere over the chest. Air entered well into both lungs, but the respiration was markedly shrill and tubular, both in front and behind on the right side, less so on the left. The voice had a bleating character to bystanders, and on auscultation was bronchophonic over the upper half of right side. The thyroid body remained in about the same condition as when last notedviz., uniformly enlarged, elastic, and symmetrical. The pain persisted in precisely the same situation. The patient directed attention on this day to some swellings upon his head, and on examination two firm node-like tumours were found upon the left parietal region, and two more upon the upper frontal region. These were situated in the pericranium, were only a little tender on pressure, but did not ache otherwise, and never at night. They had been noticed about a week previously by the patient himself, but he had not mentioned them.

Mr. Savory was invited to the consultation on the evening of this day, and he made a minute examination of the patient. It was decided to give quinine in three-grain doses every four hours, and to push the nourishment and wine more vigorously.

On the 18 th October dorsal decubitus was no longer possible. The pulse was 72 ; respiration 14 in the minute, and noisy. The tongue was covered all over with a thick dirty - white fur. No material wasting was observable. The quinine was well borne. A bad night ensued. On the 19 th, at 9.30 A.M., the pulse had risen to 90 , was soft, but of fair volume. Respiration 20 in the minute. No fresh glandular enlargements to be felt. The spleen was natural as to size. Air entered both lungs well; breathsounds very shrill. Tongue still more coated, and senses of smell and taste lost. The nares were dry, and inspiration through them impossible, though expiration could be managed. The attacks of pain became more frequent and severe, the sensation being compared to a feeling of dislocation. Some whiffs of chloroform were inbaled with slight relief to the paroxysms of dyspnoa. At 6 P.Mr. the pulse was 88 ; temperature $984^{\circ}$ in axilla, $986^{\circ}$ under the tongue. Two glands in the left groin had become enlarged and painful during the day, and the axillary glands were 2lso somewhat enlarged. Strong beef-tea, eggs, and port wine were given as free]y as possible. The quinine was increased to four grains and a half, with fifteen minims of tincture of perchloride of iron added to each dose. The pain now recurred at shorter intervals with increased severity, and was scarcely relieved by anodyne and hot fomentations. At midnight fifteen grains of chloral bydrate were given. Oct. 20th, at 1 A.Mr., a severe paroxysm of dyspncea occurred, accompanied with retching. The respiration was very noisy (roaring) and rapid, like that of severe spasmodic asthma, and the distress increased. The shoulders were supported, fanning was employed, and some chloroform was given to inhale. Stimulants were also administered. No relief was afforded. The lips became more and more dusky, and the arms were thrown about wildly. Respiration ceased almost suddenly. Silvester's method of artificial respiration was practised for about fifteen minutes, and brandy was injected into the rectum. All efforts were in vain.

No post-mortem examination was obtained.

Remarks. - The illness just described lasted in all about. four weeks. The family history afforded no clue whatever to the nature of it. The patient resided in a healthy country district, and had been, so far as was known, exposed to no insanitary or malarious influences. The earliest symptoms were, perhaps, referable to some irritation of the pulmonary branches of the vagi nerves. A condition of low health and feebleness bad been reached for some time previously. The first coarse nutritional derangement to be recognised was a hard but uniform enlargement of the thyroid gland; and for some time most of the symptoms appeared to be due to this as a source of mechanical disturbance. Thus the altered respiratory sounds and voice and the peculiar cough seemed to be accounted for. This enlargement gradually progressed, and the cervical lymphatio system likewise became involved. These changes, however, could not be set down to any form of inflammatory growth, neither were there any indications of their being dependent upon tubercular, syphilitic, or cancerous cachexia; for the conditions present, and the history obtained, negatived all these hypotheses. Together with the involvement of the lymphatic glands, certain changes occurred in the integument over the abdominal wall and in the pericranium; and the physical signs in the chest. afforded strong presumptive evidence of enlargement of the bronchial glands. At no period was there any splenic enlargement, and throughout the case there was absence of pyrexia. The blood also presented no signs of leukæmia. 
Death by apncea evidently ensued upon mechanical irritation of the pneumogastric nerves. The final paroxysm of dyspncea, like those which preceded it, was accompanied by simultaneous retching and partial syncope.

In the absence of an autopsy, the primary cause underlying these processes has to be sought. To anticipate a view which might perhaps plausibly be held after a consideration of the facts of the case-viz., that the symptoms betokened the presence of a malignant tumour of the anterior mediastinum or of the thyroid body itself,-the fact may here be restated, that the latter organ became soft and yielding towards the termination of the case, and at no period presented any unevenness or evidence of involving other adjacent structures. Such conditions seem to be quite incompatible with the rapid spread of a malignant growth into or around the texture of this gland.*

No more reasonable explanation offered itself than that which was adopted-viz., that, owing to some peculiar form of blood-poison, the lymphatic system, in a large measure, including the thyroid gland as a part of it, became involved, and, by mechanical interference with certain nerves, gave rise to the varied symptoms which occurred, and which eventually caused death at a somewhat early period in the case. The integumentary and pericranial tumours may likewise be referred to the same cause.

It should be noted that the paroxysms of dyspnoea were not due to uncomplicated laryngeal spasm. There was never present pure stridor of laryngeal quality, and although it is not possible to aver that there was no such element in the dyspnoea, the characters of the respiratiry trouble indicated the existence either of bronchial obstruction due to spasm, or, more probably, of spasm mixed with and dependent upon direct pressure from enlarged bronchial glands. Hence there never was any likelihood of affording even temporary relief by tracheotomy, for the obstruction was manifestly intrathoracic and beyond reach, and, further, the mechanical tension at one period exercised by the enlarged thyroid body had ceased to exist for some days before death. Had the thyroid gland continued to enlarge, and cause increased local pressure, an incision into the mesial line to relieve this might have been indicated. Direct compression by the gland upon the recurrent laryngeal nerves could hardly have proved more urgent towards the end of the case, but these branches may have been, and probably were, pressed upon by enlarged intrathoracic glands. The pain was, no doubt, of neuralgic nature, and due to pressure of glands upon a part of the brachial plexus.

Neither iodide of potassium nor quinine appeared to exert any beneficial influence upon the morbid process, and medical art was powerless to avert the bitter and untimely end of this remarkable and most distressing case.

Grafton-street, $W$.

\section{CASE OF}

ANEURISM OF THE ARCH OF THE AORTA; OBSCURITY OF THE SYMPTOMS;

DEATH FROM RUPTURE INTO THE PERICARDIUM. By HENRY BRIETZCKE, F.R.C.S.,
ASSISTANT-SURGEON to MTLLBANI PRIBON.

The following case is so instructive, and resembles so closely a case reported in THe LANCET of October 16th, by Dr. Frederick Robinson, that I venture to forward the notes for publication.

Corporal J. C_, aged thirty-one, a tall, muscular, wellbuilt man, was received into the Military division of Millbauk Prison on Sept. 22nd, 1875, under sentence of eightyfour days' imprisonment with hard labour, for deserting from the army in 18\%0. On admission he underwent the usual medical examination; he then stated that he was not feeling well, and was troubled with shortnees of breath and a heavy cough. The following notes were taken:-

* My colleague, Dr. Andrew, has reminded me of the opinion held by the late Dr. Southey Warter, of St. Bartholomew's Hospital, that eancerous growths often progress without exciting any pyrexia; and, so far, in this case this observation might have lent support to the view of malignant disease, but for other and weightier reasons this sepposition could not be entertained. See also Wunderlich on Temperature.
Present condition. - Unhealthy aspect; cicatrices of old abscesses on different parts of the body; badly nourished. Right lung: Posteriorly, puerile rough breathing; dulnees on percussion and bronchophony in right interscapular region; absolute dulness on percussion in sternal half of subclavicular region and pectoriloquy at extreme apex; heart-sounds feeble and indistinct; laryngeal cough; no pulsation, thrill, bulging, or murnur over area of dulness; no abnormal sounds over vertebral column. Under these circumstances he was admitted in to hos pital.

History. - States that he first began to be ill in February, 1875, at New York; he got wet, and had a wheezing in his chest. In July be began to be very short of breath, and then consulted several doctors; he was told he had "bronchitis and asthma, with a tendency to consumption." His voice became hoarse in August while on his way to England. He has felt uneasiness in the left side of the chest for some time, but only when lying down; for the last four months he has been obliged to lie on his right side, as he felt "smothered" if he rested on the other.

Sept. 28th.-Ordered a mixture of dilute sulphuric acid with digitalis. Not so well. Temperature $101 \cdot 2^{\circ}$; pulse 132 . Has had a rigor, followed by febrile symptoms. Had a bad night; tongue furred. Vomited two or three times; this, he says, is caused by efforts to cough up phlegm which he feels in his throat. No expectoration to speak of. Breathing slightly quickened and of a laryugeal description; he cannot lie on his left side. On being questioned, he states that he has a slight difficulty in swallowing solids, that the bolus of food appears to lodge in the gullet somewhere towards the left side in front, and that be is obliged to take fluid to wash down every mouthful; this, be says, has lasted for two or three months. Notwithstanding this statement, he took a good dinner of meat and potatoes the day after admission, and was not unusually long over it. Never had hæmoptysis; no hereditary history of phthisis; no history of injury or strain.

30th. - 9 P.M.: Pulse 120; respiration 33. Laryngeal breathing; and hard, paroxysmal, hoar'se cough. The re. spiratory murmur is very deficient all over the left lung; in fact, very little air appears to enter, although there is no dulness on percussion or sign of consolidation. No pulsation in episternal notch; no bruit; no difference in the two radials; no pain in the back or chest. Ordered vapour of conium; and to have five minims of dilute hydrocyanic acid, twelve minims of spirit of chloroform, fifteen minims of ethereal tincture of lobelia, and one drachm of compound tincture of cardamoms, in water to an ounce and a half, every six hours.

Oct. 2nd.-9.45 A.Mr. : Palse 120, full; tongue very foul ; temperature $100 \cdot 6^{\circ}$. Has had no sleep. Yesterday there was slight purulent expectoration. States that his breathing is relieved by the conium vapour. Excessive resonance on percussion over the left lung, deficient respiratory murmur, rhonchus; over the root of the lung, in the interscapular region, the breathing is extremely loud and bronchial, and the voice resounds through the stethoscope; but this is also to be found to some extent on the right side.

3rd.-11 A.Mr.: 'Face flushed and slightly dusky; orthoproa on being raised up; pulse 140 ; temperature $102^{\circ}$.1 P.M. : On carefully examining the chest, in consultation with Mr. Gover, the senior medical officer, we find absolute dulness on percussion in the right subclavicular region, with a sense of resistance to the finger, and this extends towards the sternum, especially over the second and third costal cartilages and corresponding intercostal space close to the sternum. In the right lung there is distinct vesicular murmur, and resonance on percussion; in the suprascapular region the breathing is loud and rough. During respiration the left chest scarcely rises at all; the right expands well. There is absence of respiratory murmur on the left side, and excessive resonance on percussion. Over the left interscapular region the breathing is loud and blowing. The lower intercostals on both sides fall in during respiration, and the diaphragm does not act well. No increased cardiac dulness; no pulsation or murmur. In the absence of indications of laryngeal disease, as well as of the symptoms characteristic of aneurism, we diagnosed a solid tamour, cancerous or glandular, compressing the left bronchus and irritating the left recurrent nerve.

4th.-10 A.M. : Pulse 128; bad night; cough troublesome; expectoration bronchitic and slightly purulent. Tempera. 